NOTE

\title{
Visible dye light absorption properties of processed radiographic film
}

\author{
Tsang Cheung ${ }^{1}$, Martin J Butson ${ }^{1,2,3}$ and Peter K N Yu${ }^{1}$ \\ ${ }^{1}$ City University of Hong Kong, Department of Physics and Materials Science, Kowloon Tong, \\ Hong Kong \\ 2 Illawarra Cancer Care Centre, Department of Medical Physics, Crown Street, Wollongong, \\ NSW 2500, Australia \\ E-mail: mbutson@usa.net
}

Received 9 February 2001

Published 6 July 2001

Online at stacks.iop.org/PMB/46/N197

\begin{abstract}
The visible absorption spectra of Kodak X-Omat V film, which had been exposed to various doses of radiation, have been investigated to analyse the dosimetry characteristics of the film with various densitometers. Common densitometers can use fluorescent light (broad band visible), helium-neon $(632 \mathrm{~nm})$ or other spectra of specific bandwidth. The visible absorption spectra show a slight peak in absorption at approximately $580 \mathrm{~nm}$ and another at $630 \mathrm{~nm}$ caused by the base material of the film. The optical density of the film is shown to increase almost equally at all wavelengths within the visible region with increases in applied dose. By evaluating the results for the broad band spectra and specific wavelength optical density it is shown that a relatively uniform response is expected for all densitometers that work within the visible region as well as in selected infrared wavelengths. Thus similar optical density to dose response curves for X-Omat V radiographic film should be produced for all types of densitometers, no matter what type of light source is used for illumination. Thus it is most efficient to have a densitometer with a light source suitable for radiochromic film, which can also be used with radiographic film.
\end{abstract}

\section{Introduction}

Film dosimetry in radiotherapy can depend on many parameters. Some of these include the energy or beam quality of the irradiation beam (Johns and Cunningham 1983), whether the exposure is performed parallel or perpendicular to the film (Suchowerska et al 1999) or the chemistry involved in the processing of the film (Khan 1992). Another area that can affect film dosimetry is the densitometer used and the type of light source it uses for analysis.

3 Author to whom correspondence should be addressed at: Department of Medical Physics, PO Box 1798, Wollongong 2500 NSW, Australia. 
Infrared light sources are often used for radiographic film densitometers to avoid interference with the room lighting (Metcalfe et al 1997). Fluorescent, visible light densitometers have also become widely used (Mersseman and de Wagter 1998) partly due to the introduction of radiochromic film dosimetry in radiotherapy where the optimal light source required for dosimetry should lie in the 'red' region of the visible spectrum. Radiochromic film is predominantly sensitive in the red region with two absorption peaks located at approximately $600 \mathrm{~nm}$ and at $660 \mathrm{~nm}$ (Niroomand-Rad et al 1998). Thus a visible light densitometer can be used for both applications. This note studies the absorption spectra in the visible region for Kodak X-Omat V radiographic film after irradiation with $6 \mathrm{MV}$ x-rays and provides a comparison of absolute optical density results for various common light sources used in these visible light densitometers.

\section{Materials and methods}

Kodak X-Omat V radiographic film was used for the study of visible absorption spectra. For absorbed dose delivery, the films were positioned in a solid water (Constantinou et al 1982) phantom of dimensions $30 \mathrm{~cm} \times 30 \mathrm{~cm} \times 30 \mathrm{~cm}$. The phantom was placed on a Varian $2100 \mathrm{C}$ linear accelerator treatment couch with the upper surface at the isocentre $(100 \mathrm{~cm})$. The film was positioned at a depth $D_{\max }$ of $1.5 \mathrm{~cm}$ for $6 \mathrm{MV}$ x-rays and doses of $0 \mathrm{cGy}, 10 \mathrm{cGy}, 20 \mathrm{cGy}$, $30 \mathrm{cGy}$ and $50 \mathrm{cGy}$ were given with the film perpendicular to the central axis of the beam. The film was processed in a Kodak M35 X-Omat processor in a single batch. The absorption spectra results were measured using a Shimadzu UV-160 UV-visible recording spectrophotometer. Its wavelength range is $200 \mathrm{~nm}$ to $1100 \mathrm{~nm}$ and it has a spectral bandwidth of $3 \mathrm{~nm}$ with an accuracy of $\pm 0.5 \mathrm{~nm}$. The films were scanned five times each and results showed a mean error of less than $0.5 \%$. The films were held in quartz holding containers. Measurements were made at $5 \mathrm{~nm}$ intervals from $400 \mathrm{~nm}$ to $750 \mathrm{~nm}$. Optical density measurements were also made on four different densitometers for comparison using the same pieces of exposed film. These include:

(a) A $660 \pm 20 \mathrm{~nm}$ LED system (converted Scanditronix) (Carolan et al 1997).

(b) A $670 \pm 5 \mathrm{~nm}$ band pass filtered Gafchromic film reader.

(c) A Vidar VXR-12 fluorescent light densitometer.

(d) A Vidar Lumiscan $75632.8 \mathrm{~nm}$ helium-neon laser scanner.

The films were scanned five times each at a well-defined point in the centre of the film for each densitometer. Comparisons are made of optical density for these various visible light source densitometers.

\section{Results and discussion}

Figure 1 shows the absorption spectra for Kodak X-Omat V film in the visible and just into the infrared region $(400-750 \mathrm{~nm})$. Increases in absorption with dose are broad band in the visible region as expected due to the optical black body nature of the film; however, two nominal peaks in the absorption spectra are located at approximately $580 \mathrm{~nm}$ and $630 \mathrm{~nm}$. Upon further examination, it was found that these two peaks are due to the inherent absorption characteristics of the base material of the radiographic film. The emulsion was totally removed from the film using bleach. The absorption properties of the base were measured and produced two nominal peaks of the same magnitude at the same wavelengths. Figure 2 shows the net optical density of the film after irradiation up to $50 \mathrm{cGy}$ applied dose. Results show that the net increase in optical density with dose is approximately linear (within 10\%) over all wavelengths from $400 \mathrm{~nm}$ to $750 \mathrm{~nm}$. The largest net change in OD was recorded at the lower wavelengths around 


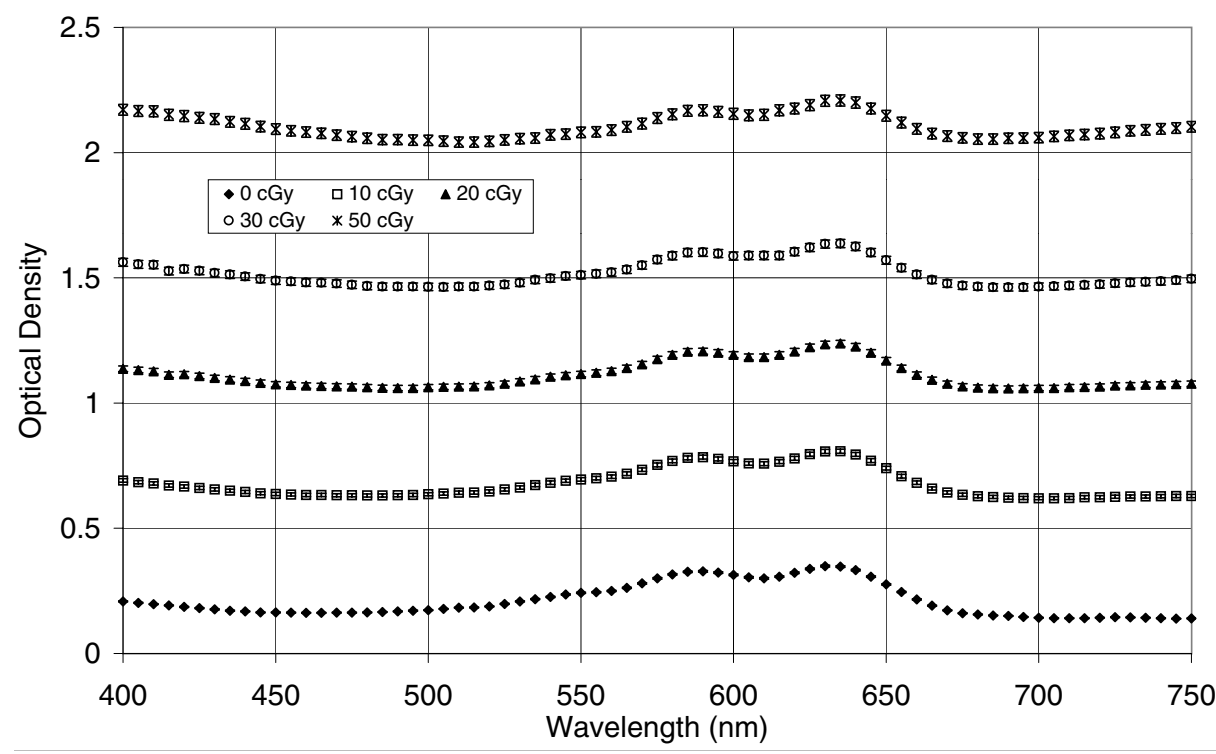

Figure 1. Dye light absorption spectrum for radiographic film irradiated to various dose levels up to $50 \mathrm{cGy}$.

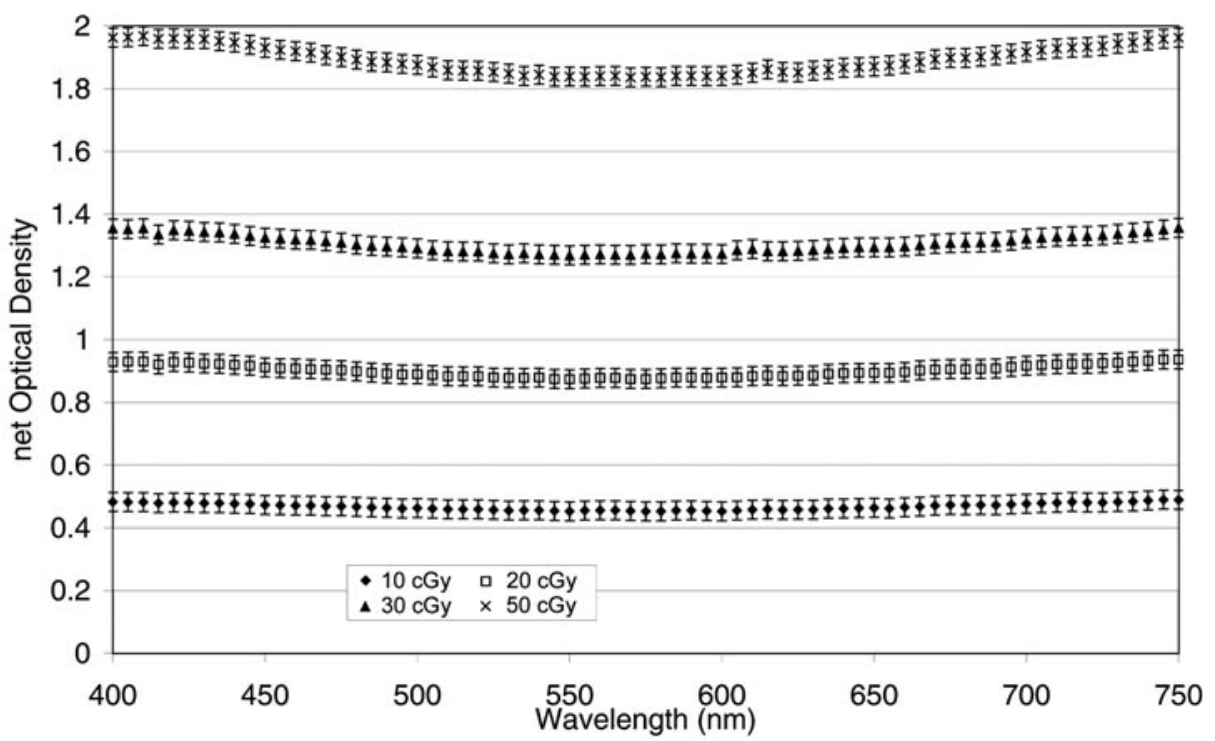

Figure 2. Net optical density of radiographic film as a function of wavelength for various absorbed doses up to $50 \mathrm{cGy}$.

$400 \mathrm{~nm}$. These results show that any visible light densitometer used for analysis of X-Omat V radiographic film should produce similar results for net OD measurements. This is different from the results for radiochromic film where the film produces a major absorption peak in the 'red' region and thus the readout wavelength for the densitometer used can produce significant differences in the measured optical density. To quantify these assumptions four commonly 
Table 1. Optical density results for exposed Kodak X-Omat V film at specific wavelengths.

\begin{tabular}{llllll}
\hline \multirow{2}{*}{$\begin{array}{l}\text { Densitometer } \\
\text { light source }\end{array}$} & \multicolumn{5}{c}{ Absolute optical density } \\
\cline { 2 - 6 } & $0 \mathrm{cGy}$ & $10 \mathrm{cGy}$ & $20 \mathrm{cGy}$ & $30 \mathrm{cGy}$ & $50 \mathrm{cGy}$ \\
\hline Fluorescent & $0.203 \pm 0.007$ & $0.679 \pm 0.011$ & $1.112 \pm 0.010$ & $1.509 \pm 0.013$ & $2.105 \pm 0.015$ \\
$660 \pm 20 \mathrm{~nm}$ & $0.229 \pm 0.009$ & $0.695 \pm 0.013$ & $1.128 \pm 0.012$ & $1.528 \pm 0.017$ & $2.110 \pm 0.015$ \\
$670 \pm 5 \mathrm{~nm}$ & $0.175 \pm 0.010$ & $0.645 \pm 0.013$ & $1.079 \pm 0.014$ & $1.479 \pm 0.021$ & $2.067 \pm 0.023$ \\
$632 \mathrm{~nm}$ & $0.348 \pm 0.0142$ & $0.808 \pm 0.0135$ & $1.237 \pm 0.0153$ & $1.636 \pm 0.0178$ & $2.208 \pm 0.028$ \\
\hline & & & Net optical density & & \\
Densitometer & $0 \mathrm{cGy}$ & $10 \mathrm{cGy}$ & $20 \mathrm{cGy}$ & $30 \mathrm{cGy}$ & $50 \mathrm{cGy}$ \\
light source & 0 & $0.476 \pm 0.013$ & $0.909 \pm 0.012$ & $1.31 \pm 0.015$ & $1.90 \pm 0.017$ \\
\hline Fluorescent (broad band) & 0 & $0.467 \pm 0.016$ & $0.899 \pm 0.015$ & $1.30 \pm 0.019$ & $1.88 \pm 0.017$ \\
$660 \pm 20 \mathrm{~nm}$ & 0 & $0.471 \pm 0.016$ & $0.904 \pm 0.017$ & $1.31 \pm 0.023$ & $1.89 \pm 0.025$ \\
$670 \pm 5 \mathrm{~nm}$ & 0 & $0.460 \pm 0.02$ & $0.889 \pm 0.021$ & $1.29 \pm 0.023$ & $1.86 \pm 0.031$ \\
$632 \mathrm{~nm}$ & 0 & & & & \\
\hline
\end{tabular}

used light sources were evaluated and the results are quoted in table 1 . As can be seen, the absolute optical density recorded on each densitometer varies slightly due to the characteristic wavelength of each light source. Also shown are the results for net optical density of each film with the four densitometers. Results show a close match for change in net optical density for all densitometers. There was a variation of less than $5 \%$ between all densitometers. These results highlight the fact that radiographic film is not wavelength sensitive in its densitometry output. This is unlike radiochromic film, which is highly wavelength specific. Thus it is most efficient to have a densitometer with a light source suitable for radiochromic film, which can also be used for radiographic film.

\section{Conclusions}

$\mathrm{X}$-Omat V radiographic film has nominal absorption peaks at approximately 530 and $630 \mathrm{~nm}$ in the visible region. Upon irradiation, there is less than $10 \%$ variation in net optical density over the visible spectral region. All four visible light densitometers tested for use with radiographic film produced results for net optical density in close agreement with each other. Radiographic film is predominately not sensitive to wavelength in the visible region. Radiochromic film is wavelength sensitive. Consequently, it would appear to be most efficient to have a densitometer with a light source suitable for radiochromic film, but which can also be used for radiographic film.

\section{Acknowledgment}

This work has been fully supported by a grant from the Research Grants Council of HKSAR, China (project no CityU 1137/00P).

\section{References}

Constantinou C, Attix F and Paliwal B 1982 A solid water phantom material for radiotherapy x-ray and gamma ray beam ray calculations Med. Phys. 9 436-41

Carolan M, Butson M, Herrmann K, Mathur J N and Metcalfe P 1997 Conversion of an infrared densitometer for radiochromic film analysis Australas. Phys. Eng. Sci. Med. 20 185-9

Johns H and Cunningham J 1983 The Physics of Radiology 4th edn (Springfield, IL: Thomas) 
Khan F 1992 The Physics of Radiation Therapy 2nd edn (London: Williams and Wilkins)

Mersseman B and de Wagter C 1998 Characteristics of a commercially available film digitizer and their significance for film dosimetry Phys. Med. Biol. 43 1803-12

Metcalfe P, Kron T and Hoban P 1997 The Physics of Radiotherapy X-rays From Linear Accelerators (Madison, WI: Medical Physics Publishing)

Niroomand-Rad A, Blackwell C, Coursey B, Gall K, Galvin J, McLaughlin W, Meigooni A, Nath R, Rodgers J and Soares C 1998 Radiochromic film dosimetry: recommendation of AAPM Radiation Therapy Task Group 55 Med. Phys. 25 2093-115

Suchowerska N, Hoban P, Davison A and Metcalfe P 1999 Perturbation of radiotherapy beams by radiographic film: measurements and Monte Carlo simulations Phys. Med. Biol. 44 1755-65 